from Dorset, noted particularly that the large plant, now found to have the low chromosome number, occurred in quantity on the damp roadside banks characteristic of Marshwood Vale, whereas the smaller darker-leaved one $(2 n=56)$ grew in wet meadows". It should. also be noted that the ehromosome number of Cardamine pratensis from Merton was found by Lawrence to be. $2 n=30$ (thus agreeing with counts made by Lövkvist ${ }^{5}$ and Hussein ${ }^{2,3}$ and with unpublished counts by myself for the lower chromosome number form) and not $2 n=32$ as stated by Haskell, although Lawrence did suggest that it may have arisen from $2 n=32$ by chromosome fusion.

Watercress should surely not have been included as an example of chromosome-races since, although Manton ${ }^{6}$ suggested that the forms with $2 n=32,48$ and 64 were diploid, triploid and tetraploid races of the same species, later work by Howard and Manton ${ }^{2,8}$ showed conclusively that there are two quite distinct species of watercress, Nasturtium officinale sensu stricto with a chromosome number of $2 n=32$ and N. microphyllum (or N. uniseriatum as Howard and Manton called it) with $2 n=64$. The form with $2 n=48$ is the interspecific hybrid $N$. microphyllum $\times$ officinale. Moreover, it was shown quite conclusively that $N$. microphyllum was an allotetraploid and therefore that any differences between it and $N$. officinale were most likely to be due not to polyploidy but to the influence of other, unfortunately still unknown, parent species of $N$. microphyllum. Further, as Airy Shaw ${ }^{9}$ has pointed out, the tetraploid species of watercress, namely, N. microphyllum, had been distinguished for many years by several European botanists as a distinct species.

It should also be noted that diploid watercress, namely $N$. officinale sensu stricto, is a perennial and not an annual as Haskell states and that Haskell's description of $N$. microphyllum as perennial winter watercress is misleading in another respect. The brown or so-called winter cress of the commercial grower is the hybrid N. microphyllum $\times$ officinale and not $N$. microphyllum, which is not cultivated ${ }^{10}$. Also, green or so called summer cress, $N$. officinale, is cultivated for winter use at the present time on a very large scale and the terms 'winter' and 'summer' cress are therefore to a large extent misnomers. It may be, as Haskell suggests, that $N$. officinale occurs in areas with a higher mean rainfall and $N$. microphyllum in areas with a lower mean rainfall; but when we mapped our records ${ }^{11}$ for the distribution of the two species, it was not apparent to either Mr. A. G. Lyon or me. The suggested distribution is, moreover, an exception to the general rule proposed by Haskell in his last paragraph that tetraploids, not diploids, occur in the wetter places; but, if correct, it is easily understandable when we remember, as has been pointed out earlier, that $N$. microphyllum is an allotetraploid and not an autotetra. ploid. There is, however, further evidence about the distribution of the two watercress species which Haskell has omitted. Both Airy Shaw ${ }^{12}$ and Howard and Lyon ${ }^{11}$ give reasons for suggesting that $N$. microphyllum can tolerate lower $p \mathrm{H}$ values and calcium concentrations than $N$. officinale. It is hoped that further observations on this point will be published soon in Biological Flora accounts for the two species. Lastly, in discussing the distribution of watercress, it must always be remembered that, in addition to being a wild plant, watercress is cultivated in the south of England and that for many centuries prior to its cultivation it was eaten as a salad plant by man.

Plant Breeding Institute,

H. W. HOWARD

School of Agriculture, Cambridge.

1 Haskell, G., Nature, 167, 628 (1951).

Hussein, F., Nature, 161, 1015 (1948).

${ }^{8}$ Hussein, F., Rep. Bot. Soc. Brit. Isl. Conference of 1948, p. 77.

- Lawrence, W. J. C., Genetica, 13, 183 (1931).

"Lövkvist, B., Hereditas, 33, 421 (1947).

- Manton, I., Z. Indult. Abstamm. Vererb., 69, 132 (1935).

7 Howard, H. W., and Manton, I., Nature, 146, 303 (1940).

8 Howard, H. W., and Manton, I., Ann. Bot., N.S., 10, 1 (1946).

- Atry Shaw, H. K., Kew Bull., No. 1, 39 (1947).

${ }^{10}$ Howard, H. W., J. Min. Agric., 53, 453 (1947).

${ }^{11}$ Howard, H. W., and Lyon, A. G., Watsonia, 1, 228 (1950).

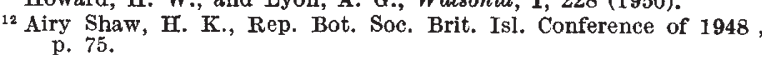

I AM indebted to Dr. H. W. Howard for criticisms and comments on my survey of the ecology of British chromosome-races ${ }^{1}$. The following points may also be added.

(1) I am pleased to learn of Miss Hussein's studies on the distribution of Cardamine pratensis in Britain. However, in her map ${ }^{2}$ she did not relate the widespread distribution of the higher chromosome-race and the restricted southerly distribution of the lower race to colonization following retreat of the ice.

(2) Lawrence ${ }^{3}$ gave $2 n=30$ for the Merton $C$. pratensis and interpreted this as reduction from 32 through chromosome fusion. I put $2 n=32$ to avoid confusion with genuine aneuploidy due to actual loss of chromosomes.

(3) Dr. Howard's criticism of my using the term 'chromosome-race' with regard to Nasturtium species and their hybrid is of much wider significance. Darlington ${ }^{4}$ has pertinently asked recently whether the chromosomes fit the species, and the problem of polyploid races within and between species has now been discussed at length by Löve ${ }^{5}$. He believes that all chromosome-races should be recognized as distinct species (even if morphological differences are slight), except asexually reproducing higher, uneven hybrids. Löve maintains that all chromosome-races show morphological differences when carefully exam. ined and uses the term 'polyplotype' to refer to a polyploid regardless of whether it is an auto- or allopolyploid. This is useful, as Stebbins $^{6}$ has already indicated that many so-called auto-polyploids could be interpreted as allo-polyploids.

(4) Manton ${ }^{7}$ referred to the summer watercress crop as being diploid and the winter crop as triploid. She said there was a marked tendency for diploids to behave as annuals unless conditions were especially favourable in the autumn, and ease of perennation was in part at least responsible for the use of the higher polyploid in winter. Dr. Howard's more recent observations will therefore clarify this point.

\section{G. HASkELI}

John Innes Horticultural Institution, Bayfordbury, Hertford.

${ }^{1}$ HaskelI, G., Nature, 167, 628 (1951).

${ }^{2}$ Hussein, F., Rep. Bot. Soc. Brit. Isl. Conf. of 194४, p. $7 \%$

${ }^{3}$ Lawrence, W. J. C., Genetica, 13, 183 (1931).

- Darlington, C. D., Nature, 167, 662 (1951).

${ }^{5}$ Löve, A., Caryologia, 8, 263 (1951).

'Stebbins, G. I., "Adv. in Genet.", 1, 403 (1947).

${ }^{7}$ Manton, I., Z. Indukt. Abstamm. Vererb., 69, 132 (1935). 